\title{
Role of Diaphragm Ultrasound When NIV Fails in COPD Exacerbations
}

In this issue of Respiratory CARE, Cammarota et $\mathrm{al}^{1}$ explored the usefulness of diaphragm ultrasound in 22 subejcts admitted with a COPD exacerbation who required noninvasive ventilation (NIV). They obtained ultrasound measurements before initiating NIV and after the first and second hours of treatment. NIV failure was defined as $\mathrm{pH}<7.35$ at $2 \mathrm{~h}$ after initiation. At each time point, diaphragm excursions in the success group were nearly twice those of the failure group (Fig. 1, upper panels). Diaphragmatic excursions did not change over time, yet both groups experienced similar decreases in tachypnea and dyspnea. After $1 \mathrm{~h}$ of treatment, diaphragm excursion was a stronger predictor of NIV failure than $\mathrm{pH}$ and arterial partial pressure of carbon dioxide $\left(\mathrm{P}_{\mathrm{aCO}_{2}}\right)$. NIV failure, however, did not impact intubation rate (no subject required intubation), hospital stay, or mortality. The investigators concluded that diaphragm ultrasound can be used to assess the diaphragm during COPD exacerbations and that decreased diaphragmatic excursion may predict NIV failure.

The results of Cammarota et $\mathrm{al}^{1}$ align with previous studies on the feasibility of diaphragm ultrasonography during COPD exacerbations., ${ }^{2,3}$ The authors also extend those results by showing that it is possible to obtain images at several time points after hospital admission without interfering with patient care. The most intriguing finding, however, is the reported association between decreased diaphragmatic excursions and NIV failure. It would be tempting to speculate that decreased excursions are caused by worse hyperinflation in the failures. A mechanistic link between hyperinflation and decreased diaphragmatic excursions is not supported by several lines of investigation. In healthy subjects, acute hyperinflation achieved through the application of CPAP does not decrease but, instead, increases diaphragmatic excursions. ${ }^{4}$ Diaphragmatic excursions in clinically stable hyperinflated patients with COPD and in healthy subjects are similar.,5,

\footnotetext{
The authors have disclosed no conflicts of interest.
}

Correspondence: Hameeda Shaikh MD, Division of Pulmonary and Critical Care Medicine, Hines Veterans Affairs Hospital, 111N, 5th Avenue and Roosevelt Road, Hines, IL 60141. E-mail: Hameeda.Shaikh@ va.gov.

DOI: $10.4187 /$ respcare. 07523
If not hyperinflation, what else could have reduced diaphragmatic excursions? Decreased muscle recruitment is unlikely because hypercapnia is associated with an increased capacity to recruit the diaphragm. ${ }^{7}$ Fatigue is doubtful because experimental data do not support a link between respiratory failure and diaphragmatic fatigue. ${ }^{8}$

\section{See the Original Study on Page 1469}

Cammarota et $\mathrm{al}^{1}$ did not monitor expiratory muscle recruitment accordingly, so it is impossible to comment on whether the decreased excursions were caused by greater diaphragm afterload. ${ }^{9}$

On the basis of this study, can we state that patients with a COPD exacerbation and decreased diaphragmatic excursion are destined to fail NIV? No. This is a small pilot study and is simply hypothesis-generating. To this we add some additional observations. From NIV initiation to the first hour of treatment, $\mathrm{P}_{\mathrm{aCO}_{2}}$ in the failure group did not decrease, yet the pressure support was not increased. The lack of NIV titration is puzzling for 2 reasons. Most practitioners would consider increasing NIV support. The definition of NIV failure was based only on arterial blood gases. The usual definition of NIV failure is the requirement of endotracheal intubation or death..$^{3,10,11}$ No subject in this study ${ }^{1}$ required endotracheal intubation, which is also highly atypical. ${ }^{10-13}$

The changes in diaphragmatic thickness between end of exhalation and end of inhalation in the success and failure group were similar (Fig. 1, lower panels). This contrasts with the study by Marchioni et al, ${ }^{3}$ in which one third of subjects had diaphragmatic dysfunction (defined as tidal thickening of the diaphragm of $<20 \%$ ). Diaphragmatic dysfunction was associated with higher risk of NIV failure (defined as the need for intubation or death); $35 \%$ of the subjects required intubation. Factors that may account for the differences in intubation rates include disease severity and diaphragmatic dysfunction. In the study by Marchioni et al, ${ }^{3}$ subjects had worse APACHE II scores, respiratory acidosis, and tachypnea. In the study by Cammarota et al, ${ }^{1}$ no subject had a tidal thickening of the diaphragm of $<20 \%$.

Cammarota et $\mathrm{al}^{1}$ raise the possibility that diaphragmatic impairment, as suggested by the smaller diaphragmatic excursions, may be an early marker of NIV failure. 


\section{EDITORIALS}
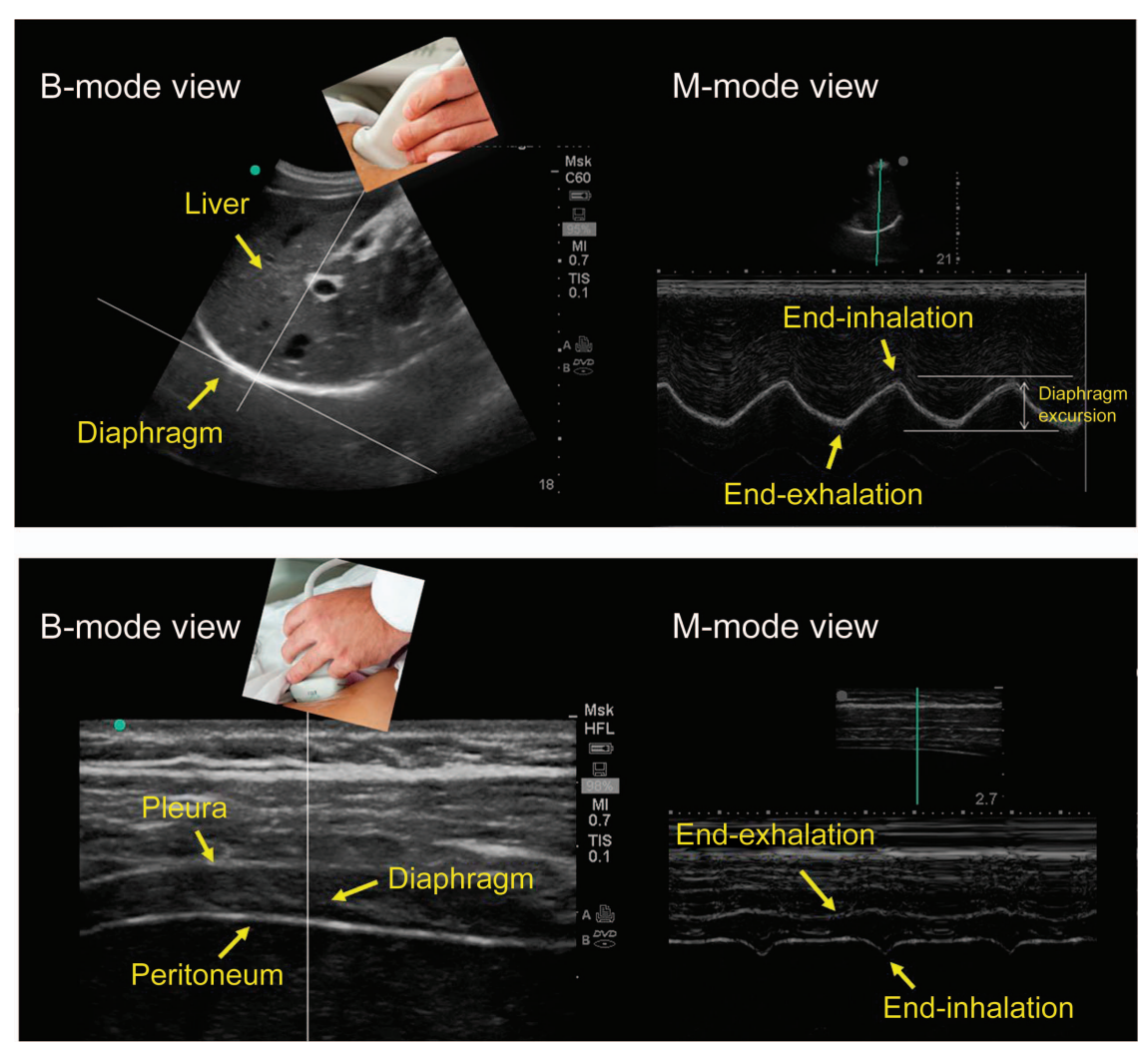

Fig. 1. Ultrasound images of the diaphragm using the right subcostal view (upper panels) and the intercostal view (lower panels) during resting breathing. (Left upper panel) Dome of the diaphragm in bright-mode (B-mode; left upper panel) and motion-mode (M-mode; right upper panel). As the diaphragm contracts, the dome moves towards the ultrasound probe. The larger the caudal displacement of the diaphragm, the greater the diaphragmatic contribution to tidal breathing. (Lower panels) Diaphragm in the zone of apposition. In B-mode (left lower panel), the diaphragm appears as a three-layer structure. In M-mode (right lower panel), the diaphragm is thinnest at endexhalation and thickness at end-inhalation; stronger diaphragmatic inspiratory efforts are associated with greater tidal thickening of the diaphragm.

Many other factors, besides impaired respiratory muscle function, can make delivery of NIV unsuccessful. These factors include worsening gas exchange, ${ }^{14}$ cardiac dysfunction, ${ }^{15}$ and psychological distress. ${ }^{16}$ Determining why a particular patient fails NIV requires an astute clinician. Few aspects of critical care medicine are more dependent on diagnostic acumen and individualized care than supporting patients with COPD exacerbations with NIV.

\section{Hameeda Shaikh Franco Laghi}

Division of Pulmonary and Critical Care Medicine Hines Veterans Affairs Hospital (111N) Hines, Illinois

Division of Pulmonary and Critical Care Medicine Loyola University Chicago, Stritch School of Medicine Maywood, Illinois

\section{REFERENCES}

1. Cammarota G, Sguazzotti I, Zanoni M, Messina A, Colombo D, Vignazia GL, et al. Diaphragmatic ultrasound assessment in subjects with acute hypercapnic respiratory failure admitted to the emergency department. Respir Care 2019;64(12):1469-1477.

2. Antenora F, Fantini R, Iattoni A, Castaniere I, Sdanganelli A, Livrieri F, et al. Prevalence and outcomes of diaphragmatic dysfunction assessed by ultrasound technology during acute exacerbation of COPD: a pilot study. Respirology 2017;22(2):338344.

3. Marchioni A, Castaniere I, Tonelli R, Fantini R, Fontana M, Tabbì $\mathrm{L}$, et al. Ultrasound-assessed diaphragmatic impairment is a predictor of outcomes in patients with acute exacerbation of chronic obstructive pulmonary disease undergoing noninvasive ventilation. Critical Care 2018;22(1):109.

4. Soilemezi E, Koco E, Tsimpos C, Tsagourias M, Savvidou S, Matamis D. Effects of continuous positive airway pressure on diaphragmatic kinetics and breathing pattern in healthy individuals. Respirology 2016;21(7):1262-1269.

5. Kleinman BS, Frey K, VanDrunen M, Sheikh T, DiPinto D, Mason $\mathrm{R}$, Smith T. Motion of the diaphragm in patients with chronic obstructive pulmonary disease while spontaneously breathing versus during positive pressure breathing after anesthesia and neuromuscular blockade. Anesthesiology 2002;97(2):298-305.

6. Gorman RB, McKenzie DK, Pride NB, Tolman JF, Gandevia SC. Diaphragm length during tidal breathing in patients with chronic obstructive pulmonary disease. Am J Respir Crit Care Med 2002; 166(11):1461-1469. 


\section{EDITORIALS}

7. Topeli A, Laghi F, Tobin M. The voluntary drive to breathe is not decreased in hypercapnic patients with severe COPD. Eur Respir J 2001;18(1):53-60.

8. Laghi F, Cattapan SE, Jubran A, Parthasarathy S, Warshawsky P, Choi YS, Tobin MJ. Is weaning failure caused by low-frequency fatigue of the diaphragm? Am J Respir Crit Care Med 2003;167(2): 120-127.

9. Laghi F, Shaikh HS, Morales D, Sinderby C, Jubran A, Tobin MJ. Diaphragmatic neuromechanical coupling and mechanisms of hypercapnia during inspiratory loading. Respir Physiol Neurobiol 2014; 198:32-41.

10. Brochard L, Mancebo J, Wysocki M, Lofaso F, Conti G, Rauss A, et al. Noninvasive ventilation for acute exacerbations of chronic obstructive pulmonary disease. N Engl J Med 1995;333(13):817822.

11. Stefan MS, Shieh MS, Pekow PS, Hill N, Rothberg MB, Lindenauer PK. Trends in mechanical ventilation among patients hospitalized with acute exacerbations of COPD in the United States, 2001 to 2011. Chest 2015;147(4):959-968.

12. Lindenauer PK, Stefan MS, Shieh M-S, Pekow PS, Rothberg MB, Hill NS. Outcomes associated with invasive and noninvasive venti- lation among patients hospitalized with exacerbations of chronic obstructive pulmonary disease. JAMA Internal Medicine 2014;174: (12)1982-1993.

13. Chandra D, Stamm JA, Taylor B, Ramos RM, Satterwhite L, Krishnan JA, et al. Outcomes of noninvasive ventilation for acute exacerbations of chronic obstructive pulmonary disease in the United States, 1998-2008. Am J Respir Crit Care Med 2012;185(2):152159.

14. Bellani G, Laffey JG, Pham T, Madotto F, Fan E, Brochard L, et al. Noninvasive ventilation of patients with acute respiratory distress syndrome. Insights from the LUNG SAFE Study. Am J Respir Crit Care Med 2017;195(1):67-77.

15. Bellone A, Monari A, Cortellaro F, Vettorello M, Arlati S, Coen D. Myocardial infarction rate in acute pulmonary edema: noninvasive pressure support ventilation versus continuous positive airway pressure. Crit Care Med 2004;32(9):1860-1865.

16. Muriel A, Peñuelas O, Frutos-Vivar F, Arroliga AC, Abraira V, Thille AW, et al. Impact of sedation and analgesia during noninvasive positive pressure ventilation on outcome: a marginal structural model causal analysis. Intensive Care Med 2015;41(9):1586-1600. 